\title{
Characteristics of prevalent and new COPD cases in Greece: the GOLDEN study
}

This article was published in the following Dove Press journal:

International journal of COPD

20 July 2015

Number of times this article has been viewed

\section{Eirini Mitsiki' \\ Eleni Bania² \\ Christos Varounis' \\ Konstantinos I \\ Gourgoulianis ${ }^{2}$ \\ Evangelos C Alexopoulos 3}

'Medical Department, Novartis Hellas, Athens, ${ }^{2}$ Department of Respiratory Medicine, Medical School, University of Thessaly, University Hospital of Larissa, Larissa, ${ }^{3}$ School of Social Sciences, Hellenic Open University, Athens, Greece
Correspondence: Eirini Mitsiki Medical Department, Novartis Hellas, I2th Km National Road No I, Athens, Greece

Tel +302102897392

Email eirini.mitsiki@novartis.com
Background: Greece has one of the highest rates of smoking and chronic obstructive pulmonary disease (COPD) in Europe.

Aim: The study aimed to record both the disease characteristics among a sample of Greek COPD patients and the nationwide rates of newly diagnosed COPD cases.

Methods: In this noninterventional, epidemiological cross-sectional study, a representative nationwide sample of 45 respiratory centers provided data on the following: 1) the demographic and clinical characteristics of COPD patients and 2) newly diagnosed COPD cases monitored over a period of 6 months by each physician.

Results: Data from 6,125 COPD patients were collected. Advanced age (median age: 68 years), male predominance (71.3\%), largely overweight status with median body mass index $(B M I)=27.5 \mathrm{~kg} / \mathrm{m}^{2}$, high percentage of current and ex-smokers $(89.8 \%)$, and presence of comorbidities $(81.9 \%)$ were evident in the sample. According to the Global Initiative for Chronic Obstructive Lung Disease (GOLD) 2011 criteria, majority of the COPD patients had moderate or severe airflow limitation $(61 \%)$. Severity of airflow limitation was significantly associated with older age, male sex, obesity, ex-smoking status, and presence of comorbidity (all $P$-values $<0.001)$. A total of $61.3 \%$ of the patients received medication, mostly bronchodilators $(64.4 \%)$ and fixed-dose combinations of long-acting $\beta_{2}$-agonists and inhaled corticosteroids (39.9\%), while $35.9 \%$ reported taking medication on demand. The majority $(81.1 \%)$ of patients reported a preference for fewer inhalations of their bronchodilator therapy. Based on the mixedeffect Poisson model, the rate of newly diagnosed COPD cases was estimated to be $18.2 \%$ (95\% confidence interval: 14.9-22.3) per pulmonologist/3 months. Of those newly diagnosed, the majority of patients had mild or moderate airflow limitation (78.2\%).

Conclusion: The Greek Obstructive Lung Disease Epidemiology and health ecoNomics study reflected the real-life profile of COPD patients and provided evidence on the profile of new COPD cases in Greece. Various demographic factors were delineated, which can assist in designing more effective diagnostic and management strategies for COPD in Greece.

Keywords: COPD, characteristics, newly diagnosed, epidemiology, prevalent cases, new cases, health care system, health care management, nationwide sampling

\section{Introduction}

Chronic obstructive pulmonary disease (COPD) is characterized by persistent airflow limitation that is usually progressive and associated with an enhanced chronic inflammatory response in the airways and the lung to noxious particles or gases. ${ }^{1}$ According to the Global Initiative for Chronic Obstructive Lung Disease (GOLD) report of 2014, COPD is a common preventable and treatable disease in which exacerbations and comorbidities contribute to the overall severity in individual patients. ${ }^{1}$ COPD has been identified as the third leading cause of death globally, ${ }^{2}$ and in $2010,4.8 \%$ of the population was diagnosed with COPD worldwide. ${ }^{3}$ Though alarming, these figures only partly represent the burden of the disease because a significant proportion of 
patients remain undiagnosed or misdiagnosed..$^{4-6}$ In the US and Europe, the rate of underdiagnosis was estimated to range from $12 \%$ to $86 \% .^{7-9}$ The underutilization of spirometry as a diagnostic tool, the lack of awareness of physicians and patients about the clinical features of COPD (which includes breathlessness, chronic cough, and sputum production), ${ }^{10}$ and the difficulty in differential diagnosis between COPD and asthma contribute significantly to this wide range of undiagnosed and misdiagnosed COPD patients. ${ }^{11-13}$ Additionally, comorbidities that are commonly present along with COPD further hinder the detection of the disease, ${ }^{9}$ and although COPD is a primary cause of death in some cases, it is often likely to be considered a contributing factor. ${ }^{14}$ There is increasing evidence that early diagnosis and early treatment of COPD lead to improvements in lung function and quality of life, as well as a reduced risk of exacerbations. ${ }^{15}$

In Europe, prevalence rates of COPD were estimated to range between $2.1 \%$ and $26.1 \%$ depending on the country, age group, and methods used. ${ }^{16}$ In Greece, COPD prevalence was estimated to range between $3 \%$ and $18.4 \% .{ }^{17-21}$ The variations observed in the prevalence rates are mainly due to the differences in the diagnostic methods (symptoms, physician reports, and spirometry), definition of COPD, age and sex distribution, and other population characteristics evaluated in each study.
This study - the first in Greece to our knowledge - aimed to 1 ) estimate the nationwide rates of newly diagnosed COPD cases and 2) assess a plethora of characteristics of COPD patients, including smoking habits, disease severity, compliance to treatment, and comorbidity, to raise treating physicians' awareness on the diagnosis and effective management of COPD in Greece.

\section{Methods}

\section{Study design}

The Greek Obstructive Lung Disease Epidemiology and health ecoNomics (GOLDEN) study was a noninterventional, nationwide epidemiological cross-sectional study conducted in Greece over a 6-month period.

To estimate the nationwide rate of newly diagnosed cases of COPD, both hospital-based and private respiratory medicine physicians were included in the study. Sampling was performed in three steps (details described by Papaioannou et $\mathrm{al}^{22-26}$ ): 1) the expected incident and prevalent COPD cases were estimated in each prefecture of Greece (52 administrative areas covering the whole country) and in total; 2) the expected incident COPD cases were estimated per pulmonologist in each prefecture; and lastly 3 ) on the basis of the ratios of expected COPD cases per pulmonologist per prefecture, three levels of sampling zones were created (Figure 1).

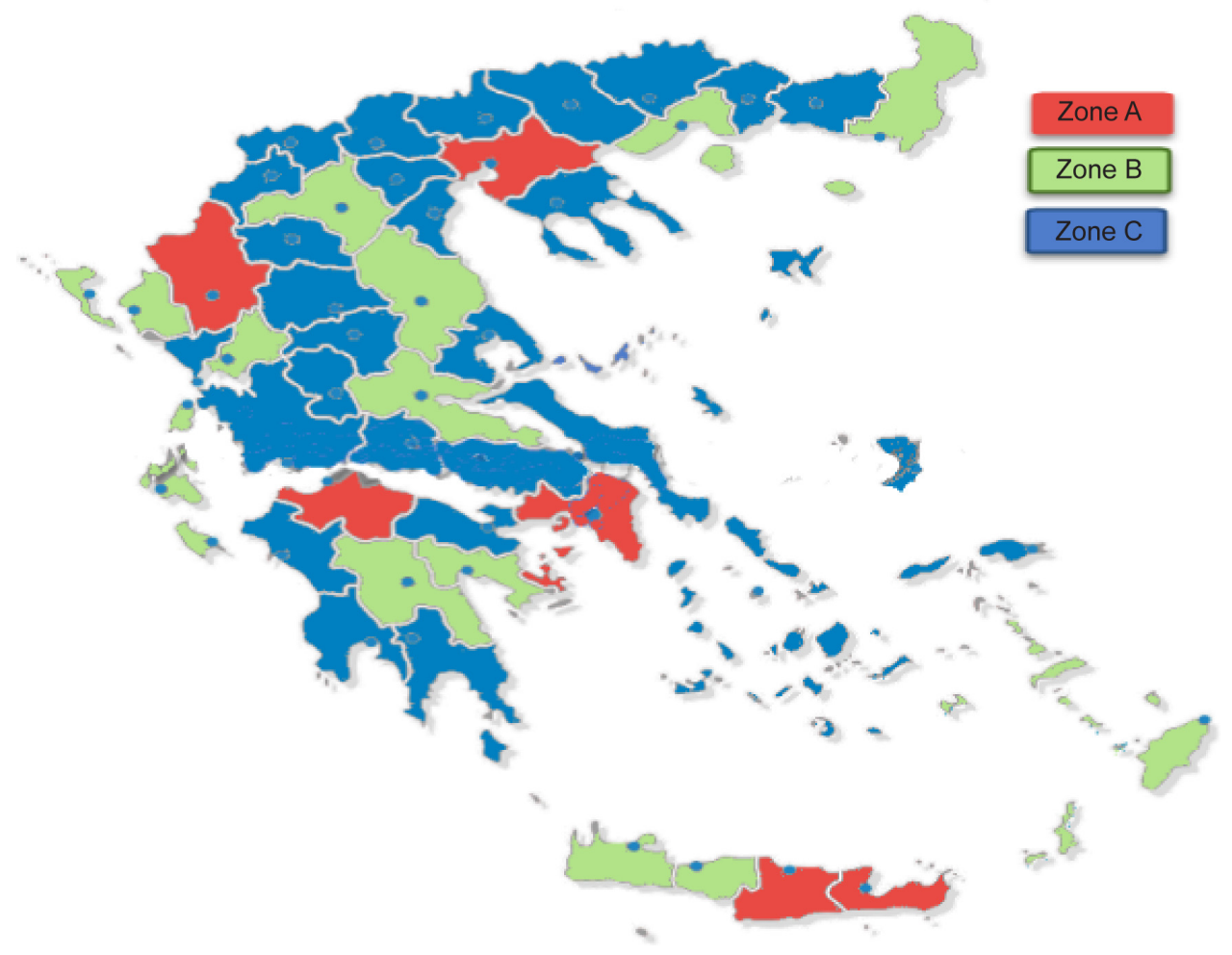

Figure I Map of Greece showing the sampling zones from which data were collected.

Notes: Zone A, areas with very large hospitals, very high density of respiratory medicine physicians, and low ratios of expected COPD cases per physician; Zone B, areas with large respiratory medicine departments and many private practitioners; Zone C, all other areas with mostly aging rural populations and few respiratory medicine physicians. 
Zone A: areas with very large hospitals, very high density of respiratory medicine physicians, and low ratios of expected COPD cases per physician; Zone B: areas with large respiratory medicine departments and many private practitioners; and Zone C: all other areas with mostly aging rural populations and few respiratory medicine physicians.

Pulmonologists from 45 respiratory medicine departments throughout Greece participated in the study. In total, 199 pulmonologists (124 private practitioners and 75 hospital doctors) provided data for this study. The total number of pulmonologists in Greece is approximately 1,800. According to this number, the sample of pulmonologists that participated in the study represents $\sim 11 \%$ of the total pool of the specialty. Data collection was performed over a period of 6 months (October 2010-March 2011). During the 6 months of the study period, each pulmonologist was asked 1) to invite the first 30 consecutive COPD patients visiting their clinic/office and who satisfied the inclusion and exclusion criteria to register for the study and 2) to monitor all newly diagnosed cases (cases diagnosed for the first time as having COPD during the specific study period) for a period of 24 weeks.

\section{Patients}

Patients could be recruited in the GOLDEN study if they provided their written informed consent and fulfilled the following inclusion and exclusion criteria:

Inclusion criteria were as follows: patients $>40$ years of age, with a diagnosis of COPD, based on GOLD 2011 criteria, ${ }^{11}$ and with the ability to provide data on their medical history. Exclusion criteria consisted of patients who had participated in a similar study a month prior to their enrollment or had asthma.

Ex-smokers were defined as smokers who had quit smoking for at least 12 months. Smoking history was measured by pack-years, defined as the number of cigarettes smoked per day divided by 20 and multiplied by the number of years of smoking. According to their smoking history, subjects were classified into three categories: never-smokers, ex-smokers, and current smokers. Compliance to therapy was assessed from physicians according to the monthly prescription of medication and the patients' and/or relatives' reporting on the regular use of the prescribed medication.

Pre- and postbronchodilation spirometry measurements were performed in all study subjects according to the routine monitoring of COPD patients in daily clinical practice. Forced expiratory volume in 1 second $\left(\mathrm{FEV}_{1}\right)$, forced vital capacity (FVC), and the $\mathrm{FEV}_{1} / \mathrm{FVC}$ ratio were recorded. Postbronchodilator values ( 30 minutes after the administration of
$400 \mu \mathrm{g}$ salbutamol with a spacer) were used for the evaluation of airflow severity, according to GOLD 2011 guidelines (Stage 1: mild COPD, $\mathrm{FEV}_{1} \geq 80.0 \%$ predicted; Stage 2: moderate COPD, $50.0 \% \leq \mathrm{FEV}_{1}<80.0 \%$ predicted; Stage 3: severe COPD, $30.0 \% \leq \mathrm{FEV}_{1}<50.0 \%$; Stage 4 : very severe $\mathrm{COPD}$, either $\mathrm{FEV}_{1}<30.0 \%$ or $\mathrm{FEV}_{1}<50.0 \%$ predicted with chronic respiratory failure). ${ }^{11}$

A second data set included patients with "newly diagnosed" COPD who were first diagnosed during the study period (patients who were referred for the first time to a pulmonologist with diagnosis established through spirometry). The number of newly diagnosed patients was recorded through the retrospective completion of questionnaires that corresponded to a once-per-week evaluation of the new patients for the total study duration of 6 months. In calendar months, the data collection phase lasted from September to March. The characteristics of the newly diagnosed patients recorded in this study included sex, age, disease type (bronchitis/emphysema) and airflow limitation (according to GOLD 2011 classification), place of residence, and smoking history.

The protocol was approved by the ethics committees of the participating research centers and the National Organization for Medicines. The study was designed, implemented, and reported in accordance with the International Conference on Harmonisation of Technical Requirements for Registration of Pharmaceuticals for Human Use (ICH) Harmonized Tripartite Guidelines for Good Clinical Practice, with applicable local regulations (including European Directive 2001/83/EC and US Code of Federal Regulations Part 21), and in accordance with the ethical principles according to the Declaration of Helsinki.

\section{Statistical methods and analysis}

Categorical variables were presented using frequency and rate, whereas continuous variables were presented using descriptive statistics (median and interquartile range [IQR]).

The rate ratios of the newly diagnosed patients were estimated using the mixed-effect Poisson model. Dependence of the rate of newly diagnosed cases with COPD on the prefectures, geographic divisions, hospitals, employment of the pulmonologist (hospital- or private-based practice), and season was also determined.

The analysis of COPD diagnosis rate was based on the hypothesis that the number of new COPD cases follows a Poisson distribution. In order to model the repeated observations per pulmonologist (assumed to affect variability), a mixed-effects Poisson model was applied. The random effect was assumed to follow the gamma distribution. 


\section{Results}

\section{Demographic characteristics of prevalent COPD cases (I st data set)}

Data from 6,125 patients were collected in the study. The baseline and clinical characteristics of the total sample are shown in Table 1 . The median age of the study participants was 68 years (IQR: 60.0-75.0) and the male-to-female ratio was 2.5:1. The median duration of COPD was 10 years (IQR: $5.0-15.0)$. Never-smokers accounted for only $10.2 \%$ of the evaluated patients. A large proportion of the enrolled patients $(18 \%)$ were newly diagnosed, many of whom had significant airflow limitation at the time of diagnosis. According to GOLD 2011 criteria, the majority of the patients were assessed with moderate or severe airflow limitation $(35.4 \%$ and $25.6 \%$, respectively).

Approximately $82 \%$ reported at least one concomitant disease, with the most common comorbid condition being hypertension $(55.3 \%)$.

Table I Demographic and clinical characteristics of the prevalent cases

\begin{tabular}{|c|c|c|c|}
\hline Demographic characteristics & Total $(\mathrm{N}=6,125)^{\mathrm{a}}$ & $\begin{array}{l}\text { “Old" cases* } \\
(\mathrm{N}=\mathbf{4 , 8 5 0 )}\end{array}$ & $\begin{array}{l}\text { Cases }(\%) \text { first diagnosed } \\
\text { within the past year } \\
(\mathrm{N}=I, 064)\end{array}$ \\
\hline Male/female & $4,367 / I, 758$ (7I.3/28.7) & $3,490 / 1,360(72 / 28)$ & $720 / 344(67.7 / 32.3)$ \\
\hline Duration of COPD (years) & $10.0(5.0,15.0)$ & $10.0(5.0,15.0)$ & - \\
\hline \multicolumn{4}{|l|}{ Body mass index ${ }^{b}$} \\
\hline Normal $(18.5-25$ kg/m²) & I,574 (25.9) & $\mathrm{I}, 245(25.9)$ & $277(26.2)$ \\
\hline Overweight $\left(25-30 \mathrm{~kg} / \mathrm{m}^{2}\right)$ & $2,715(44.7)$ & $2,133(44.3)$ & $495(46.8)$ \\
\hline Obese $\left(>30 \mathrm{~kg} / \mathrm{m}^{2}\right)$ & I,78I (29.3) & $1,436(29.8)$ & $286(27.0)$ \\
\hline \multicolumn{4}{|l|}{ Smoking status $(\mathrm{N}=5,999)$} \\
\hline Current smokers & $2,869(47.8)$ & $2,126(44.6)$ & $676(64.8)$ \\
\hline Ex-smokers & $2,519(42)$ & $2,155(45.2)$ & $27 \mid(26.0)$ \\
\hline Never-smokers & $611(10.2)$ & $488(10.2)$ & $96(9.2)$ \\
\hline \multicolumn{4}{|l|}{ Diagnosis $(\mathrm{N}=5,9 \mid 4)$} \\
\hline Chronic bronchitis & $2,856(48.3)$ & $2,260(46.6)$ & $596(56.0)$ \\
\hline Emphysema & $801(13.5)$ & $659(13.6)$ & $142(13.3)$ \\
\hline Mixed disease & $2,092(35.4)$ & $1,808(37.3)$ & $284(26.7)$ \\
\hline Undefined respiratory disease & $165(2.8)$ & $123(2.5)$ & $42(3.9)$ \\
\hline \multicolumn{4}{|c|}{ GOLD 20 I I classification of severity of airflow limitation $(N=6, \mid 14)$} \\
\hline I & $1,181(19.3)$ & $755(15.6)$ & $398(37.4)$ \\
\hline 2 & $2,167(35.4)$ & $1,705(35.2)$ & $399(37.5)$ \\
\hline 3 & $1,567(25.6)$ & $1,302(26.8)$ & $198(18.6)$ \\
\hline 4 & $1,199(19.6)$ & $1,088(22.4)$ & $69(6.5)$ \\
\hline Number of exacerbations in the past year & $2.0(0.0,3.0)$ & - & - \\
\hline Would prefer the inhaled bronchodilator & $4,832(81.1)$ & $3,978(83.2)$ & $691(70.3)$ \\
\hline \multicolumn{4}{|l|}{ therapy to include fewer inhalations } \\
\hline \multicolumn{4}{|l|}{ Compliance to therapy } \\
\hline Never/almost never & $3,242(54.5)$ & $2,527(52.4)$ & $604(65.1)$ \\
\hline$<3$ times a month & $1,276(21.5)$ & $1,088(22.6)$ & $143(15.4)$ \\
\hline I time a week & $666(11.2)$ & $570(11.8)$ & $70(7.5)$ \\
\hline$>$ I time a week & $483(8.1)$ & $415(8.6)$ & $56(6.0)$ \\
\hline Almost every day & $277(4.7)$ & $218(4.5)$ & $55(5.9)$ \\
\hline Respiratory failure-type I & $1,422(23.4)$ & $1,213(25.2)$ & $142(13.4)$ \\
\hline Respiratory failure-type II & $624(10.3)$ & $557(11.6)$ & $43(4.1)$ \\
\hline Use of nebulizer & $1,316(21.6)$ & $\mathrm{I}, 188(24.5)$ & $73(6.9)$ \\
\hline Noninvasive mechanical ventilation ${ }^{\mathrm{b}}$ & $201(3.3)$ & $156(3.2)$ & $27(2.5)$ \\
\hline Therapy with oxygen & $1,048(17.1)$ & $976(20.1)$ & $52(4.9)$ \\
\hline \multicolumn{4}{|l|}{ Concomitant diseases } \\
\hline 0 & $\mathrm{I}, 093(18.2)$ & $792(16.6)$ & $269(25.7)$ \\
\hline I & I,567 (26.1) & $\mathrm{I}, 186(24.8)$ & $336(32.1)$ \\
\hline 2 & $1,430(23.8)$ & $\mathrm{I}, 130(23.7)$ & $239(22.8)$ \\
\hline 3 & $982(16.4)$ & $829(17.4)$ & $128(12.2)$ \\
\hline $4+$ & $934(15.6)$ & $841(17.6)$ & $76(7.3)$ \\
\hline \multicolumn{4}{|l|}{ Common comorbid conditions } \\
\hline Hypertension & $3,379(55.3)$ & $2,797(57.7)$ & $470(44.2)$ \\
\hline Diabetes mellitus & $1,253(20.6)$ & $\mathrm{I}, 034(21.4)$ & 177 (I6.7) \\
\hline Heart failure & $1,185(19.4)$ & $1,021(21.1)$ & $119(11.2)$ \\
\hline Gastroesophageal reflux & $934(15.3)$ & $767(15.8)$ & $144(13.6)^{b}$ \\
\hline
\end{tabular}

Notes: ${ }^{a}$ Data are presented as median (interquartile ranges) for numerical variables or as number (\%) for categorical variables. ${ }^{b}$ Differences were not statistically significant; all others were significant $(P<0.001)$. *OId" refers to cases diagnosed for at least two years.

Abbreviations: COPD, chronic obstructive pulmonary disease; GOLD, Global Initiative for Chronic Obstructive Lung Disease. 
Almost half of the patients recruited (54\%) reported going through preventative vaccination and only $2.7 \%$ of the patients were part of rehabilitation programs. The majority of the patients (61.3\%) were under maintenance treatment, mostly with bronchodilators $(64.4 \%)$. A total of $61.4 \%$ reported using inhaled corticosteroids (ICSs), while fixeddose combinations of long-acting $\beta_{2}$-agonists + ICSs were reported as maintenance treatment by $39.9 \%$ of the patients. Approximately $55 \%$ of the patients in the study reported never forgetting to take their medication. The majority $(81 \%)$ of the patients reported a preference for fewer inhalations of their bronchodilator therapy.

Differences in the characteristics of newly diagnosed and previously diagnosed COPD cases are also illustrated in Table 1. Compared to cases with an earlier diagnosis of COPD, cases diagnosed within the past year included more females, less ex-smokers, were largely classified under stages 1 and 2, less frequent diagnosis of emphysema or mixed disease, and a low number of comorbidities (Table 1). Overall, the compliance to therapy was better among newly diagnosed cases, but a high percentage of patients forgot to take their medication regularly compared to the previously diagnosed patients $(5.9 \%$ vs $4.5 \%$; Table 1$)$.
Airflow limitation severity, defined by GOLD 2011 criteria, was significantly related to older age, male sex, obesity, ex-smoker status, and presence of more concomitant diseases $(P<0.001)$ (Figure 2 and Table 2).

\section{COPD cases diagnosed during the follow up period (2nd data set) Rate of new COPD cases}

A total of 5,030 new cases of COPD were recorded by the 199 pulmonologists in a median follow-up time of 5.60 months (IQR: 5.37-5.83). The representativeness of the sample of pulmonologists per prefecture is illustrated in Table 3, while the rate of new diagnoses per prefecture is illustrated in Figure 3. The rate of newly diagnosed cases with COPD based on the mixed-effect Poisson model was 18.2 (95\% confidence interval [CI]: 14.9-22.3) per pulmonologist $/ 3$ months. Characteristics of the newly diagnosed patients with COPD are presented in Table 4.

\section{Geographical distribution of new COPD cases}

There was a statistically significant heterogeneity among pulmonologists adjusted for geographic division; rates

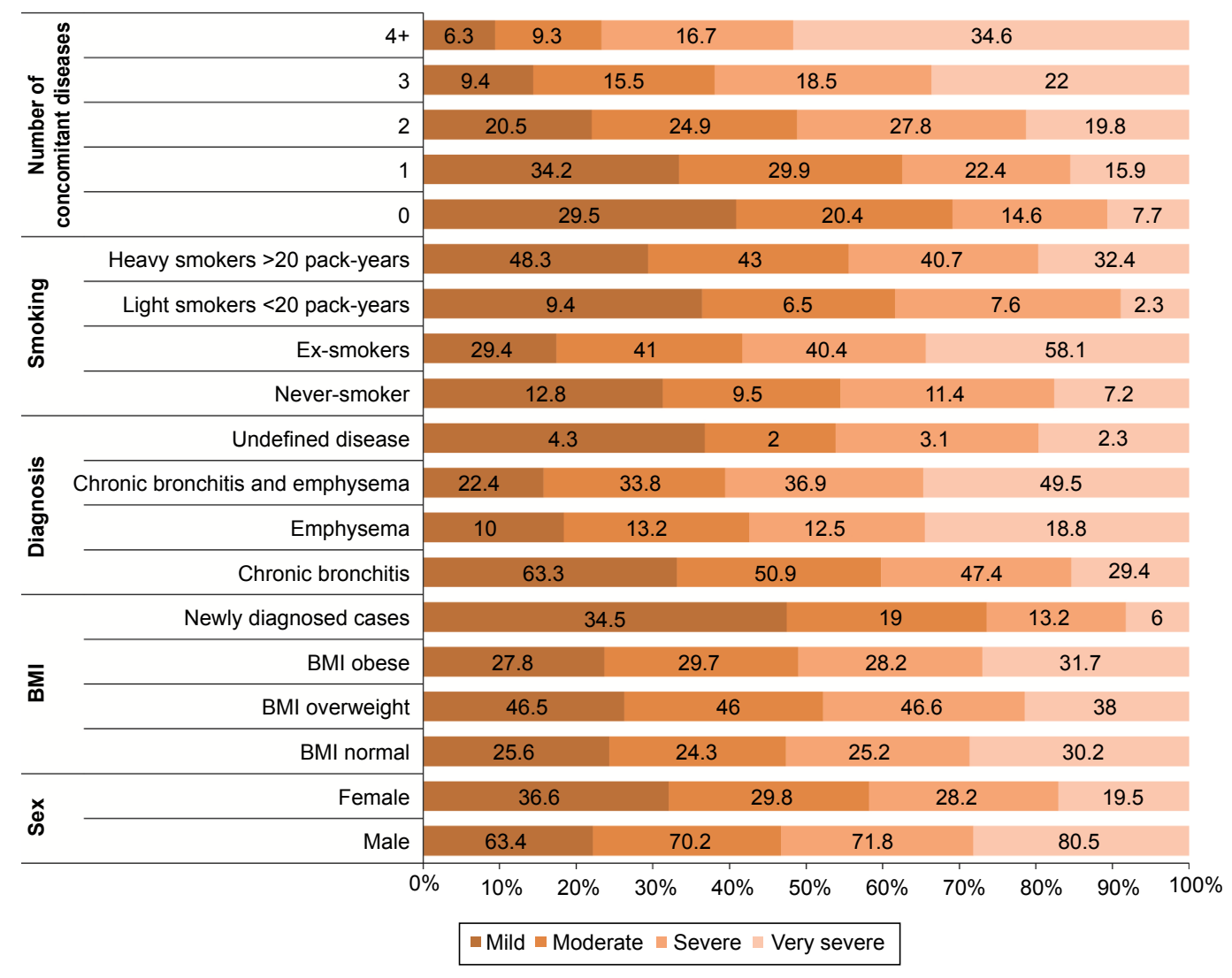

Figure 2 Descriptive statistics of the study participants according to airflow limitation as defined by GOLD guidelines. Abbreviations: BMI, body mass index; GOLD, Global Initiative for Chronic Obstructive Lung Disease. 
Table 2 Descriptive statistics of study participants according to severity of COPD (GOLD 20II)

\begin{tabular}{|c|c|c|c|c|c|}
\hline \multirow[t]{2}{*}{ Characteristics } & \multicolumn{5}{|c|}{ Severity of COPD } \\
\hline & $\mathbf{I}$ & 2 & 3 & 4 & $P$-value \\
\hline Age (years) & $63.0(53.0,71.0)$ & $67.0(59.0,74.0)$ & $67.0(60.0,75.0)$ & $72.0(66.0,78.0)$ & $<0.001$ \\
\hline Duration of COPD (years) & $5.0(2.0,10.0)$ & $8.0(4.0,11.0)$ & $10.0(5.0,15.0)$ & $10.0(6.0,19.0)$ & $<0.001$ \\
\hline Pack-years & $35.5(20.0,52.5)$ & $40.0(25.0,61.3)$ & $45.0(20.0,64.0)$ & $60.0(37.5,83.6)$ & $<0.001$ \\
\hline FEV, before bronchodilation (\%) & $80.0(70.0,87.0)$ & $65.0(58.0,71.0)$ & $52.0(43.0,67.0)$ & $43.0(29.0,54.5)$ & $<0.001$ \\
\hline FEV after bronchodilation (\%) & $82.0(75.0,90.0)$ & $68.0(61.0,75.0)$ & $58.0(47.0,74.0)$ & $46.0(32.0,59.0)$ & $<0.001$ \\
\hline Number of exacerbations in the past year & $1.0(0.0,2.0)$ & $1.0(0.0,2.0)$ & $2.0(1.0,3.0)$ & $2.0(1.0,4.0)$ & $<0.001$ \\
\hline
\end{tabular}

Notes: Data are presented as median (interquartile ranges) for numerical variables.

Abbreviations: COPD, chronic obstructive pulmonary disease; FEV , forced expiratory volume in I second; GOLD, Global Initiative for Chronic Obstructive Lung Disease.

were found to be higher in populated geographic regions of Greece. The majority of the newly diagnosed COPD patients resided in Athens (32.5\%) and other urban cities (32.3\%; urban cities defined as cities with $>10,000$ population).

Statistically significant differences were observed in the rate of newly diagnosed cases depending on the hospital ( $P=0.009$ ), setting of the pulmonologist (hospital- or private-based practice; $P<0.001)$, season $(P<0.001)$, and the level of the sampling zone $(P=0.022)$ (data provided in Tables S1-S4, respectively). A statistically significant heterogeneity existed among pulmonologists when these factors were taken into consideration $(P<0.001$ for each factor).

The multivariate analysis of the rate of new COPD diagnoses is presented in Table 5. A statistically significant difference in the incidence of newly diagnosed cases was observed among prefectures $(P<0.001)$ taking into account the setting (hospital- or private-based pulmonologist) and the seasonal influence (Table 5). Hospital-based pulmonologists reported a lower rate of newly diagnosed COPD cases compared to private-based pulmonologists (lower by $70.4 \%$ ) when the prefecture and the season were also considered $(P<0.001$; Table 5).

Table 3 Representativeness of COPD diagnoses per prefecture

\begin{tabular}{lllll}
\hline & \multicolumn{2}{l}{ Newly diagnosed } & $\begin{array}{l}\text { Population } \\
\text { as \% of total }\end{array}$ & P-value \\
\cline { 2 - 3 } & No, N (\%) & Yes, N (\%) & \\
\hline Prefecture & & & & 0.008 \\
Thrace & $219(4.6)$ & $35(3.3)$ & 5.6 & \\
Macedonia & I,052(22.1) & $214(20.4)$ & 19.8 & \\
Epirus & $86(1.8)$ & II (I.0) & 3.1 & \\
Thessaly & $286(6.0)$ & $46(4.4)$ & 6.7 & \\
Central Greece & I,86I (39.0) & $46 \mid(43.9)$ & 46.7 & \\
Peloponnese & $607(12.7)$ & I I I (I2.5) & 5.4 & \\
Aegean Islands & $180(3.8)$ & $31(3.0)$ & 5.0 & \\
lonian Islands & $82(1.7)$ & $25(2.4)$ & 1.9 & \\
Crete & $396(8.3)$ & $95(9.1)$ & 5.7 & \\
\hline
\end{tabular}

Abbreviation: COPD, chronic obstructive pulmonary disease.
The rate of new COPD diagnoses was also affected by the season, with lower reporting noted during the warmer months (lower by $18.5 \%$ ) compared to colder months, when the prefecture and the setting were taken into consideration $(P<0.001$; Table 5$)$. When all parameters of the multivariate model were considered, a statistically significant heterogeneity was observed among pulmonologists $(P<0.001 ; 95 \% \mathrm{CI}$ random effect: 1.15 [0.92-1.43]).

On the basis of the assumption that pulmonologists see the more severe cases, an additional analysis was carried out considering only GOLD 2-4 stages of COPD. The calculated rate of these cases was 10.7 (95\% CI: 8.7-13.2) per pulmonologist $/ 3$ months.

Similar to the results observed for overall cases, statistically significant differences were observed in the incidence rate of newly diagnosed cases considering only GOLD $2-4$ stages depending on the geographic divisions, setting of the pulmonologist, and season $(P<0.001$ for all factors $)$.

\section{Discussion}

The GOLDEN study has recorded data that allow for the description of various characteristics of COPD patients in Greece.

According to the current study findings, COPD was more prevalent among older adults, men, and smokers, which is consistent with findings of previous studies in the Greek population..$^{18-20}$ The current study is the first nationwide study reporting new findings since 2004 and consists of a significant sample size. Direct comparison of our results with past studies is also difficult to establish, owing to the fact that different age distributions, regions, populations, and time periods of assessment were evaluated in each study.

The findings of the current study are also in accordance with those of the studies conducted worldwide, with high COPD prevalence observed among elderly individuals, men, and smokers. ${ }^{27-31}$ However, differences were also noted. 


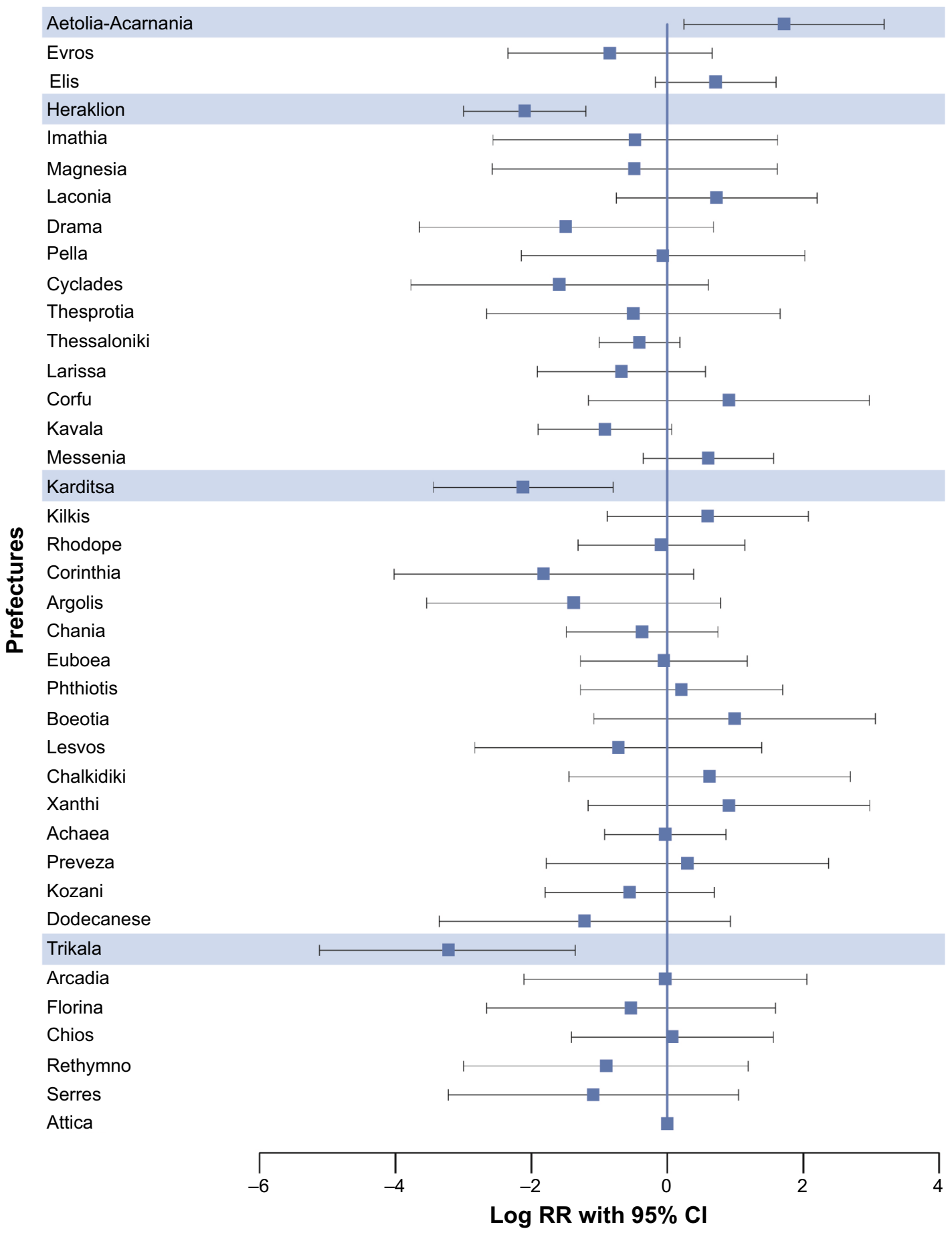

Figure 3 Dependence of the rate of newly diagnosed cases with COPD on prefectures (results from mixed-effect Poisson model).

Notes: All the prefectures studied were compared against Attica, wherein higher number of cases was reported. Highlighted data represent significant results. Log RR $>0$ indicates higher incidence, while value $<0$ indicates lower incidence.

Abbreviations: $\mathrm{Cl}$, confidence interval; COPD, chronic obstructive pulmonary disease; RR, rate ratios.

The current study in Greece observed more cases of COPD in overweight individuals, whereas studies conducted in the US and Norway reported high prevalence among underweight or severely obese individuals. ${ }^{27,29}$ In contrast to our findings, higher prevalence rates of COPD were observed among women than men in the US,,$^{30}$ while in
Africa, no significant effect of sex was seen on the prevalence of COPD. ${ }^{31}$

Interestingly, patients diagnosed within the past year were less frequently diagnosed with emphysema or mixed disease, as well as having a high number of comorbid conditions, although less in number compared to patients diagnosed earlier. 
Table 4 Characteristics of newly diagnosed patients with COPD in Greece

\begin{tabular}{|c|c|c|c|}
\hline Characteristics & Male, \% & Female, \% & Total, \% \\
\hline \multicolumn{4}{|l|}{ Disease } \\
\hline Chronic bronchitis & 50.09 & 57.71 & 52.07 \\
\hline Emphysema & 16.55 & 11.94 & 15.35 \\
\hline Chronic bronchitis and emphysema & 33.36 & 30.35 & 32.58 \\
\hline \multicolumn{4}{|c|}{ GOLD 20 I I classification of severity of airflow limitation } \\
\hline $0-1$ & 29.53 & 43.63 & 33.21 \\
\hline 2 & 46.40 & 41.15 & 45.03 \\
\hline 3 & 19.34 & 13.52 & 17.82 \\
\hline 4 & 4.74 & 1.71 & 3.95 \\
\hline \multicolumn{4}{|l|}{ Smoking status } \\
\hline Smokers & 77.41 & 75.11 & 76.74 \\
\hline Ex-smokers & 19.88 & 19.33 & 19.72 \\
\hline Never-smokers & 2.71 & 5.56 & 3.54 \\
\hline \multicolumn{4}{|l|}{ Age (years) } \\
\hline$\leq 44$ & 1.54 & 1.53 & 1.54 \\
\hline $45-49$ & 4.63 & 7.68 & 5.52 \\
\hline $50-54$ & 10.09 & 13.01 & 10.95 \\
\hline $55-59$ & 18.45 & 23.28 & 19.86 \\
\hline $60-64$ & 22.41 & 25.51 & 23.31 \\
\hline $65-69$ & 21.10 & 17.28 & 19.98 \\
\hline 70-74 & 12.73 & 7.41 & 11.18 \\
\hline $75-79$ & 6.09 & 2.90 & 5.16 \\
\hline$\geq 80$ & 2.95 & 1.41 & 2.50 \\
\hline
\end{tabular}

Abbreviations: COPD, chronic obstructive pulmonary disease; GOLD, Global Initiative for Chronic Obstructive Lung Disease.

These study findings support the significance of early diagnosis and intervention among heavy smokers and males, as early diagnostic and educational strategies could enhance disease management and compliance to treatment. ${ }^{32}$

Interestingly, half of the patients in the GOLDEN study were assessed as having mild or moderate airflow limitation (Stages 1 and 2), and according to the new GOLD guidelines, they would be expected to fall in groups A and B if they had either $<2$ exacerbations in the previous year or no hospitalizations. However, a significant percentage of these patients reported being under treatment with ICSs (which is recommended in patients with severe or very severe airflow limitation and/or hospitalizations or $\geq 2$ exacerbations per year; groups $\mathrm{C}$ and $\mathrm{D}$ ), indicating a low rate of adherence to global recommendations by the treating physicians. ${ }^{1}$ In addition, the low rates of preventive vaccination and rehabilitation highlight the significance of increasing awareness of these interventions for the effective management of COPD, as recommended by GOLD. ${ }^{1}$

High rates of nonadherence to COPD treatment were also recorded in our study. The high proportion of patients forgetting to take their medication might be due to the presence of multiple comorbidities and thus they may need to take multiple treatments, related to higher age, while complex
Table 5 Multivariate analysis of the rate of new diagnoses of COPD

\begin{tabular}{llll}
\hline & RR & $\mathbf{9 5 \%} \mathbf{C l}$ & P-value \\
\hline $\begin{array}{l}\text { Prefecture } \\
\text { Central Greece }\end{array}$ & $\mathrm{I}$ & & $<0.00 \mathrm{I}$ \\
Thrace & 0.973 & $(0.390,2.427)$ & 0.954 \\
Peloponnese & $\mathrm{I} .167$ & $(0.687, \mathrm{I} .984)$ & 0.567 \\
Crete & 0.286 & $(0.154,0.534)$ & $<0.00 \mathrm{I}$ \\
Macedonia & 0.578 & $(0.362,0.924)$ & 0.022 \\
Thessaly & 0.307 & $(0.139,0.678)$ & 0.003 \\
Aegean Islands & 0.576 & $(0.212,1.568)$ & $0.28 \mathrm{I}$ \\
lonian Islands & 5.526 & $(0.642,47.569)$ & 0.120 \\
Epirus & 0.68 & $(0.146,3.174)$ & 0.624 \\
Hospital & & & \\
No & $\mathrm{I}$ & & \\
Yes & 0.296 & $(0.194,0.450)$ & $<0.00 \mathrm{I}$ \\
Warmer months (April-September) & \\
No & $\mathrm{I}$ & & \\
Yes & 0.815 & $(0.769,0.864)$ & $<0.001$ \\
\hline No &
\end{tabular}

Notes: Results from the mixed-effects Poisson model.

Abbreviations: $\mathrm{Cl}$, confidence interval; $\mathrm{COPD}$, chronic obstructive pulmonary disease; $R R$, rate ratios.

dosing schedules and perception of limited efficacy can also cause low compliance rates. ${ }^{33}$ Extra care should therefore be taken in educating COPD patients on the significance of compliance to therapy to reduce symptoms and future risk. In agreement with previously reported data, ${ }^{17,34-36}$ the most commonly reported comorbidities in the studied population were hypertension, diabetes mellitus, heart failure, and gastroesophageal reflux. Sensitization of primary care physicians treating these conditions among the common COPD symptoms might provide a means to refer them for lung function testing and earlier COPD diagnosis. ${ }^{37}$

The rate of newly diagnosed COPD cases observed was much higher than expected based on the international literature and $>5$ times higher than that calculated during the design of the study. Recent data from a Dutch study reported 1,713 newly diagnosed cases of COPD in a mean follow-up time of 3.4 years ( standard deviation $= \pm 3.2$ years).$^{38} \mathrm{~A}$ longitudinal cohort study conducted in Ontario, Canada, estimated the annual incidence rates of COPD from 1996 to 2007 to be 61,998 to $55,903 .{ }^{39}$ A prospective cohort study identified 648 cases of incident COPD after a median follow-up time of 11 years in the Netherlands. ${ }^{40}$ Compared to the incidence rates reported in the above-mentioned studies, the GOLDEN study recorded a total of 5,030 new cases of COPD in a mean follow-up time of 5.60 months. These differences in incidence rates can perhaps be attributed to differences in the definitions of COPD, health care settings, geographical divisions, characteristics of the study populations (with respect to age, sex, and smoking status), and methodology used for 
assessing COPD. An interesting finding is that the highest rates of newly diagnosed cases were recorded in urban areas and mostly by private pulmonologists. This might be indicative of the reduced rates of COPD diagnosis in rural areas, especially due to the lack of specialized pulmonologists to perform spirometry.

Because the majority of the newly diagnosed patients had mild or moderate airflow limitation (78.2\%), it is necessary to implement routine spirometric evaluations to identify the disease in its earlier stages. Detection of these patients at early stages of airflow limitation might assist in the optimization of disease management in the long term. As smoking is one of the main contributing causes of COPD,${ }^{41}$ spirometry could be used in current and ex-smokers with or without respiratory symptoms as a diagnostic tool to evaluate the possible presence of COPD. These measures may identify patients with undiagnosed COPD, and early diagnosis can lead to adequate management of such cases.

As with all observational studies, the GOLDEN study has strengths and weaknesses. The foremost strength is that this is the first study to assess newly diagnosed cases of COPD throughout Greece in a large sample size, allowing the collation of detailed information on various patient aspects. Furthermore, the use of spirometry in our study provides an additional validation of the classification of disease severity. The limitation of our study is the possibility that our results might have suffered an overestimation bias (overreporting bias) most probably due to the retrospective recording of newly diagnosed COPD cases and the high per capita consumption of cigarettes among the Greek population.

\section{Conclusion}

The GOLDEN study reflects the real-life profile of COPD patients in Greece. The study has observed predominance of the elderly, men, smokers, overweight and obese individuals, moderate airflow limitation, and high comorbidity among COPD patients. In addition, results revealed a high proportion of newly diagnosed cases of COPD, relatively low compliance to treatment guidelines, high rates of nonadherence to COPD treatment, and an increased preference for simpler treatment options (fewer inhalations). Substantial rates of new COPD diagnoses in Greece were also documented, indicating the need to increase awareness around the disease and its effective management. These data provide a framework that could be used by health professionals to adequately diagnose and manage COPD. However, more studies in well-defined samples with similar patient populations, using standard diagnostic tools are required to effectively integrate strategies to prevent and manage COPD in Greece.

\section{Acknowledgments}

The study was funded by Novartis Hellas. The authors thank the following pulmonary medicine physicians for their contribution to the study. Following is the list of GOLDEN investigators: Theodora Kerenidi, Eleni Karetsi, Nikolaos Poulakis, Chrysovalantis Papageorgiou, Aggeliki Rapti, Georgios Tsoukalas, Vasileios Tzilas, Georgatou Niki, Konstantinos Marosis, Haris Mpitsakou, Penny Moraiti, Mihail Toumpis, Asimina Gaga, Theoplasti Grigoratou, Evangelia Hondrou, Maria Kokkala, Dimitrios Veldekis, Fotios Vlastos, Georgios Heilas, Aspasia Chrisofaki, Stylianos Mihailidis, Vasiliki Filaditaki, Vlassios Polychronopoulos, Anastasia Amfilohiou, Georgios Tatsis, Paraskevi Katsaounou, Spyridon Papiris, Stylianos Loukidis, Eleni Gaki, Konstantinos Katis, Aikaterini Haniotou, Efstathia Evangellopoulou, Theodosios Panagiotakopoulos, Panagiotis Stratopoulos, Theoharis Dimou, Dimitris Georgopoulos, Aikaterini Varela, Spyridon Ganiaris, Nikolaos Siafakas, Nikolaos Tzanakis, Georgios Meletis, Emmanouil Ntaoukakis, Aggeliki Damianaki, Konstantinos Kallergis, Georgios Hrysofakis, Spyros Logothetis, Kyriakos Hainis, Stylianos Podaras, Eleni Nikolopoulou, Panagiotis Kritis, Konstantinos Karkanis, Foivos Kokkinis, Christina Koumpaniou, Karmen MantaStahouli, Stavroula Ponirea, Nikolaos Harokopos, Nikolaos Galanis, Evangelia Fouka, Evangelia Serasli, Venetia Tsara, Lazaros Sihletidis, Marianna Kakoura, Stavros Vogiatzis, Anna Gavriilidou, Kleio Eleftheriou, Despoina Kosmidou, Vasiliki Dimitriadou, Dimitris Zois, Sotiria Laparidou, Antonios Antoniadis, Vasileios Ioannidis, Emmanouil Liolios, Stavroula Mpousmoukilia, Dimosthenis Mpouros, Georgios Patlakas, Efmorfia Tsiantou, Ignatios Katsenis, Thomas Arhontis, Athanasios Mitsios, Konstantinos Perifanos, Konstantinos Kostikas, Evridiki Karakasi, Ioannis Tsiotsios, Thoedoros Tsaias, Vasilis Adamidis, Damianos Damianakos, Anastasia Pella, Theofilos Pehlivanidis, Eleni Servakou, Panagiotis Hatziapostolou, Aikaterini Kazakou, Thomas Karapetsas, Prodromos Hatzivlasiou, Maria Katertzi-Moshoni, Stergios Pavlidis, Sotiria Sevastou, Foteini Simoglou, Stylianos Kaloudis, Iraklis Titopoulos, Ilias Tselepis, Hrysoula Kourtidou, Ioannis Tsimpoukelis, Dimitrios Zordinis, Iosif Elemenoglou, Efthimia Papadopoulou, Stavros Tryfon, Alexandros Filandrianos, Vasiliki Tzelepi, Dimitra Theodoridou-Tsanaka, Eleni Thomoglou, Konstantinos Haritopoulos, Kosmas Papahristou, Apostolos Arvanitidis, Argyro Theodorikakou, Amalia Ferentinou, Aggelos 
Nikitas, Hristos Tzafaridis, Anastasia Samakovli, Ourania Georgoudi, Miltiadis Markatos, Grigorios Georgoudakis, Stylianos Kalogerakis, Panagiotis Mamatzakis, Konstantinos Hatzakis, Nikolaos Paterakis, Ioannis Politis, Evangelos Zigakis, Astrinos Ieronimakis, Mihalis Arvanitakis, Kalliopi Sigelaki, Marouso Stathppoulou, Evangelia Daniil, Mihail Psihakis, Nikolaos Karvounas, Georgios Kotrogiannis, Georgios Koulouris, Eleftherios Vrouvakis, Ifigeneia Topaka, Panagiotis Theodosiou, Eirini Savva, Alexandros Konstantinidis, Panagiotis Kokkonis, Christina Leontaridi, Stefania Katsoulidi, Vasiliki Lazou, Panagiota Ksilogianni, Stylianos Strakantounas, Vasileios Kyriakidis, Magda Gouni, Panagiota Traka, Alexandros Tsakatikas, Anastasia Spata, Lemonia Karoutsou, Nikolaos Svolis, Nikiforos Papatsimpas, Panagiotis Karkaletsis, Alexandros Kazamias, Sofia Alexandraki, Konstantinos Nikas, Emmanouil Tziralidis, Pantelis Avarlis, Mihail Sakellaropoulos, Dimitrios Fotopoulos, Georgios Nikolopoulos, Athanasios Aggelopoulos, Georgios Tsarouhis, Aglaia Skouta, Ioannis Laskaris, Panagiotis Kyriazis, Antonia Konsta, Panagiotis Koursarakos, Leonidas Stellas, Antonis Hristopoulos, Nikolaos Karatzas, Dionysios Papalexatos, Vasileios Topallianidis, Antionios Antoniadis, Gerasimos Apollonatos, Athanasia Sampani, Styliani Mytilinaiou, Eleni Fotopoulou, Ioannis Maragos, Antonios Kladogenis, Vasileios Konstantaras, Georgia Kotantoula, Theodoros Nikoloudis, Hara Kyriakaki, Nikolaos Malamos, Panagiota Hatzigiannaki, Eirini Koumpa, Dimosthenis Tsipilis, Christina Theohari, Eirini Daskalaki, Anna Kontogianni, Panagiotis Argyriou, Tziovani Termine, Fanis Giannakas, Lampros Lampropoulos, and Olympia Chioni. The authors also acknowledge Purnima Pathak, of Novartis Healthcare Pvt, Ltd, India, for providing writing assistance in the development of this manuscript.

\section{Author contributions}

Eirini Mitsiki, Eleni Bania, Evangelos Alexopoulos, and Konstantinos Gourgoulianis were involved in the study conception and design. Konstantinos Gourgoulianis is the guarantor. Eirini Mitsiki and Eleni Bania collected the data. Evangelos Alexopoulos performed the statistical analysis of the data. Eirini Mitsiki, Christos Varounis, and Evangelos Alexopoulos prepared the manuscript. All authors provided input to study design and in drafting and revising the manuscript. All authors have read and approved the final manuscript and agreed to be accountable for all aspects of the work presented in this manuscript.

\section{Disclosure}

Eirini Mitsiki and Christos Varounis are currently working for Novartis. Eleni Bania has worked for Novartis. Evangelos C Alexopoulos held a contract with Novartis for participating in the study design and performing the statistical analysis. Konstantinos I Gourgoulianis has received investigator's fees for the GOLDEN study from Novartis. The authors report no other conflicts of interest in this work.

\section{References}

1. Global Strategy for the Diagnosis, Management and Prevention of COPD, Global Initiative for Chronic Obstructive Lung Disease (GOLD) 2014 [website on the Internet]. Available from: http://www.goldcopd. org. Accessed April 1, 2014.

2. Lozano R, Naghavi M, Foreman K, et al. Global and regional mortality from 235 causes of death for 20 age groups in 1990 and 2010: a systematic analysis for the Global Burden of Disease Study 2010. Lancet. 2012;380(9859):2095-2128.

3. Vos T, Flaxman AD, Naghavi M, et al. Years lived with disability (YLDs) for 1160 sequelae of 289 diseases and injuries 1990-2010: a systematic analysis for the Global Burden of Disease Study 2010. Lancet. 2012;380(9859):2163-2196.

4. Halbert RJ, Isonaka S, George D, Iqbal A. Interpreting COPD prevalence estimates: what is the true burden of disease? Chest. 2003;123(5): 1684-1692.

5. Pauwels RA, Rabe KF. Burden and clinical features of chronic obstructive pulmonary disease (COPD). Lancet. 2004;364(9434):613-620.

6. Halbert RJ, Natoli JL, Gano A, Badamgarav E, Buist AS, Mannino DM. Global burden of COPD: systematic review and meta-analysis. Eur Respir J. 2006;28(3):523-532.

7. Peña VS, Miravitlles M, Gabriel R, et al. Geographic variations in prevalence and under diagnosis of COPD: results of the IBERPOC multicentre epidemiological study. Chest. 2000;118(4):981-989.

8. Rudolf M. The reality of drug use in COPD: the European perspective. Chest. 2000;117(2 suppl):29S-32S.

9. Stang P, Lydick E, Silberman C, Kempel A, Keating ET. The prevalence of COPD: using smoking rates to estimate disease frequency in the general population. Chest. 2000;117(5 suppl 2):354S-359S.

10. van Schayck CP, Chavannes NH. Detection of asthma and chronic obstructive pulmonary disease in primary care. Eur Respir J Suppl. 2003; $39: 16 s-22 s$.

11. Global Strategy for the Diagnosis, Management and Prevention of COPD, Global Initiative for Chronic Obstructive Lung Disease (GOLD) 2011 [website on the Internet]. Available from: http://www.goldcopd. org. Accessed December 10, 2013.

12. Chang J, Mosenifar Z. Differentiating COPD from asthma in clinical practice. J Intensive Care Med. 2007;22(5):300-309.

13. Tinkelman DG, Price DB, Nordyke RJ, Halbert RJ. Misdiagnosis of COPD and asthma in primary care patients 40 years of age and over. J Asthma. 2006;43(1):75-80.

14. Jensen HH, Godtfredsen NS, Lange P, Vestbo J. Potential misclassification of causes of death from COPD. Eur Respir J. 2006;28(4): 781-785.

15. Price D, Freeman D, Cleland J, Kaplan A, Cerasoli F. Earlier diagnosis and earlier treatment of COPD in primary care. Prim Care Respir J. 2011; 20(1):15-22.

16. Atsou K, Chouaid C, Hejblum G. Variability of the chronic obstructive pulmonary disease key epidemiological data in Europe: systematic review. BMC Med. 2011;9:7.

17. Zachariades AG, Zachariadou T, Adamide T, Anagnostopoulou U, Georgiou A, Gourgoulianis KI. Prevalence of chronic obstructive pulmonary disease in Cyprus: a population-based study. COPD. 2012;9(3):259-267.

18. Sichletidis L, Tsiotsios I, Gavriilidis A, et al. Prevalence of chronic obstructive pulmonary disease and rhinitis in northern Greece. Respiration. 2005;72(3):270-277.

19. Tzanakis N, Anagnostopoulou U, Filaditaki V, Christaki P, Siafakas N; COPD group of the Hellenic Thoracic Society. Prevalence of COPD in Greece. Chest. 2004;125(3):892-900. 
20. Minas M, Hatzoglou C, Karetsi E, et al. COPD prevalence and the differences between newly and previously diagnosed COPD patients in a spirometry program. Prim Care Respir J. 2010;19(4):363-370.

21. Public Health Europe-European Commission-EU 2007 [website on the internet]. Available from: http://ec.europa.eu/health/ph_publication/ eb_health_en.pdf. Accessed December 10, 2013.

22. Papaioannou AI, Bania E, Alexopoulos EC, Mitsiki E, Malli F, Gourgoulianis KI. Sex discrepancies in COPD patients and burden of the disease in females: a nationwide study in Greece (Greek obstructive lung disease epidemiology and health ecoNomics: GOLDEN study). Int J Chron Obstruct Pulmon Dis. 2014;9:203-213.

23. Shibuya K, Mathers CD, Lopez AD. Chronic Obstructive Pulmonary Disease (COPD): Consistent Estimates of Incidence, Prevalence, and Mortality by WHO Region. Global Programme on Evidence for Health Policy. World Health Organization; 2001. Available from: http://www. who.int/healthinfo/statistics/bod_copd.pdf. Accessed January 15, 2014.

24. Lopez AD, Shibuya K, Rao C, et al. Chronic obstructive pulmonary disease: current burden and future projections. Eur Respir J. 2006; 27(2):397-412.

25. Hellenic Statistical Authority [website on the Internet]. Available from: http://www.statistics.gr/portal/page/portal/ESYE/PAGE-database. Accessed December 7, 2013.

26. Hellenic Thoracic Society [website on the Internet]. Available from: http://www.hts.org.gr/. Accessed December 7, 2013.

27. Waatevik M, Skorge TD, Omenaas E, Bakke PS, Gulsvik A, Johannessen A. Increased prevalence of chronic obstructive pulmonary disease in a general population. Respir Med. 2013;107(7):1037-1045

28. Sharifi H, Masjedi MR, Emami H, et al. Interim report from burden of obstructive lung disease (BOLD Study) in Tehran: prevalence and risk factors of chronic obstructive pulmonary disease. Tanaffos. 2014; 13(3):6-13.

29. Halldin CN, Doney BC, Hnizdo E. Changes in prevalence of chronic obstructive pulmonary disease and asthma in the US population and associated risk factors. Chron Respir Dis. 2015;12(1):47-60.

30. Landis SH, Muellerova H, Mannino DM, et al. Continuing to confront COPD international patient survey: methods, COPD prevalence, and disease burden in 2012-2013. Int J Chron Obstruct Pulmon Dis. 2014; 9:597-611.
31. Adeloye D, Basquill C, Papana A, Chan KY, Rudan I, Campbell H. An Estimate of the prevalence of COPD in Africa: a systematic analysis. COPD. 2015;12(1):71-81.

32. Decramer M, Celli B, Kesten S, et al; UPLIFT investigators. Effect of tiotropium on outcomes in patients with moderate chronic obstructive pulmonary disease (UPLIFT): a prespecified subgroup analysis of a randomised controlled trial. Lancet. 2009;374(9696):1171-1178.

33. Bourbeau J, Bartlett SJ. Patient adherence in COPD. Thorax. 2008; 63(9):831-838.

34. Fletcher MJ, Upton J, Taylor-Fishwick J, et al. COPD uncovered: an international survey on the impact of chronic obstructive pulmonary disease [COPD] on a working age population. BMC Public Health. 2011;11:612.

35. Garcia Rodriguez LA, Wallander MA, Tolosa LB, Johansson S. Chronic obstructive pulmonary disease in UK primary care: incidence and risk factors. COPD. 2009;6(5):369-379.

36. Goossens LM, Baker CL, Monz BU, Zou KH, Rutten-van Molken MP. Adjusting for COPD severity in database research: developing and validating an algorithm. Int J Chron Obstruct Pulmon Dis. 2011;6: 669-678.

37. Jones RC, Price D, Ryan D, et al; Respiratory Effectiveness Group. Opportunities to diagnose chronic obstructive pulmonary disease in routine care in the UK: a retrospective study of a clinical cohort. Lancet Respir Med. 2014;2(4):267-276.

38. Afonso AS, Verhamme KM, Sturkenboom MC, Brusselle GG. COPD in the general population: prevalence, incidence and survival. Respir Med. 2011;105(12):1872-1884.

39. Gershon AS, Wang C, Wilton AS, Raut R, To T. Trends in chronic obstructive pulmonary disease prevalence, incidence, and mortality in Ontario, Canada, 1996 to 2007: a population-based study. Arch Intern Med. 2010;170(6):560-565.

40. van Durme YM, Verhamme KM, Stijnen T, et al. Prevalence, incidence, and lifetime risk for the development of COPD in the elderly: the Rotterdam study. Chest. 2009;135(2):368-377.

41. Miller M, Cho JY, Pham A, Friedman PJ, Ramsdell J, Broide DH. Persistent airway inflammation and emphysema progression on CT scan in ex-smokers observed for 4 years. Chest. 2011;139(6):1380-1387. 


\section{Supplementary materials}

Table SI Dependence of the rate of newly diagnosed cases with COPD per hospital

\begin{tabular}{|c|c|c|c|}
\hline & $\mathbf{R} \mathbf{R}$ & $95 \% \mathrm{Cl}$ & $P$-value \\
\hline Hospital & & & 0.009 \\
\hline GH Ag. Dimitrios & I & & \\
\hline GH Amalia Fleming & 0.96 & $(0.179,5.159)$ & 0.962 \\
\hline GH Venizelio of Heraklion & 0.25 & $(0.036, I .75 I)$ & 0.163 \\
\hline GH of Corfu & 7.333 & $(1.487,36.169)$ & 0.014 \\
\hline $\mathrm{GH}$ of Kavala & 0.403 & $(0.090,1.81 \mathrm{I})$ & 0.236 \\
\hline GH of Kalamata & 2.4 & $(0.473,12.170)$ & 0.291 \\
\hline GH of Karditsa & 0.16 & $(0.020,1.312)$ & 0.088 \\
\hline GH of Kozani Mamatseio & 0.8 & $(0.146,4.382)$ & 0.797 \\
\hline GH of Komotini & 0.824 & $(0.155,4.366)$ & 0.820 \\
\hline \multicolumn{4}{|l|}{ Sismanogleio } \\
\hline GH of Lamia & 1.8 & $(0.325,9.982)$ & 0.501 \\
\hline GH Papanikolaou & 0.188 & $(0.034,1.041)$ & 0.056 \\
\hline GH of Pyrgos A & 0.636 & $(0.111,3.656)$ & 0.612 \\
\hline \multicolumn{4}{|l|}{ Papandreou } \\
\hline $\mathrm{GH}$ of Rethymnon & 1.208 & $(0.238,6.136)$ & 0.819 \\
\hline $\mathrm{GH}$ of Serres & 1 & $(0.186,5.374)$ & 1.000 \\
\hline GH Sismanogleio & 0.762 & $(0.190,3.046)$ & 0.700 \\
\hline $\mathrm{GH}$ of thorax diseases & 0.774 & $(0.217,2.757)$ & 0.693 \\
\hline \multicolumn{4}{|l|}{ Sotiria } \\
\hline GH of Chios Skylitseio & 1.04 & $(0.195,5.548)$ & 0.963 \\
\hline GH of Chalkida & 2.32 & $(0.457,11.780)$ & 0.310 \\
\hline GH of Chania Ag. Georgios & 0.923 & $(0.172,4.96 I)$ & 0.926 \\
\hline GUH Evaggelismos & 0.448 & $(0.099,2.03 \mathrm{I})$ & 0.298 \\
\hline GUH of Larisa & |.57| & $(0.306,8.083)$ & 0.589 \\
\hline GUH of Nikaia & 1.36 & $(0.260,7.105)$ & 0.715 \\
\hline GUH Papageorgiou & 0.455 & $(0.074,2.777)$ & 0.393 \\
\hline Special Hospital of Thorax & 0.768 & $(0.178,3.325)$ & 0.725 \\
\hline \multicolumn{4}{|l|}{ Diseases of West Greece } \\
\hline UGH Attikon & 0.56 & $(0.097,3.217)$ & 0.516 \\
\hline UGH of Heraklion Pepagni & 0.88 & $(0.162,4.770)$ & 0.882 \\
\hline $\begin{array}{l}\text { University Hospital of } \\
\text { Alexandroupolis }\end{array}$ & 1.875 & $(0.370,9.508)$ & 0.448 \\
\hline
\end{tabular}

Note: Results from mixed-effect Poisson model.

Abbreviations: $\mathrm{Cl}$, confidence interval; COPD, chronic obstructive pulmonary disease; GH, General Hospital; RR, rate ratios; UGH, University General Hospital; GUH, General University Hospital.
Table S2 Dependence of the rate of newly diagnosed cases with COPD on the setting of the pulmonologist (hospital or private based)

\begin{tabular}{llll}
\hline & RR & $95 \%$ Cl & $P$-value \\
\hline Hospital & & & \\
No & I & & \\
Yes & 0.297 & $(0.193,0.458)$ & $<0.001$ \\
\hline
\end{tabular}

Note: Results from mixed-effect Poisson model.

Abbreviations: $\mathrm{Cl}$, confidence interval; $\mathrm{COPD}$, chronic obstructive pulmonary disease; RR, rate ratios.

Table S3 Dependence of the rate of newly diagnosed cases with COPD on season

\begin{tabular}{llll}
\hline & RR & $95 \% \mathbf{C l}$ & $P$-value \\
\hline Months (April-September) & & \\
No & I & & \\
Yes & 0.817 & $(0.771,0.865)$ & $<0.001$ \\
\hline
\end{tabular}

Note: Results from mixed-effect Poisson model.

Abbreviations: $\mathrm{Cl}$, confidence interval; COPD, chronic obstructive pulmonary disease; RR, rate ratios.

Table S4 Dependence of the rate of newly diagnosed cases with COPD on the sample level

\begin{tabular}{llll}
\hline & RR & $\mathbf{9 5 \%} \mathbf{C l}$ & $P$-value \\
\hline Sample level & & & 0.022 \\
A & I & & \\
B & 0.775 & $(0.445,1.350)$ & 0.368 \\
C & 1.681 & $(1.069,2.645)$ & 0.025 \\
\hline
\end{tabular}

Note: Results from mixed-effect Poisson model.

Abbreviations: $\mathrm{Cl}$, confidence interval; $\mathrm{COPD}$, chronic obstructive pulmonary disease; RR, rate ratios.
International Journal of COPD

\section{Publish your work in this journal}

The International Journal of COPD is an international, peer-reviewed journal of therapeutics and pharmacology focusing on concise rapid reporting of clinical studies and reviews in COPD. Special focus is given to the pathophysiological processes underlying the disease, intervention programs, patient focused education, and self management protocols.

\section{Dovepress}

This journal is indexed on PubMed Central, MedLine and CAS. The manuscript management system is completely online and includes a very quick and fair peer-review system, which is all easy to use. Visit $\mathrm{http}: / /$ www.dovepress.com/testimonials.php to read real quotes from published authors. 